\title{
Anatomía del relato político: conceptualización, funciones y piezas de una herramienta comunicacional estratégica. El caso del presidente Mauricio Macri (2015-2018)
}

\author{
Gonzalo Sarasqueta $^{1}$
}

Recibido: 14-01-2020 / Aceptado: 12-11-2020

Resumen. El actual trabajo se propone delimitar, ordenar y sistematizar el conocimiento teórico vinculado al relato político. En la primera parte, después de recorrer distintos abordajes, se presenta una conceptualización de relato político. Al mismo se lo define como la estructura narrativa que emplea el jefe del poder Ejecutivo para brindarle significación, coherencia, cohesión y legitimidad a su gestión. Luego, se señalan las funciones, requisitos y fases de esta herramienta comunicacional estratégica. Acto seguido, a través de los primeros tres años de gestión del presidente argentino, Mauricio Macri, se especifican las cinco piezas que estructuran un relato político: trama, guion dicotómico, tiempo verbal, repertorio simbólico y ethos presidencial. Como conclusión, podemos deducir que dicha narrativa gubernamental se caracteriza por una trama del cambio, un conflicto entre la república y el populismo, un lenguaje prospectivo, una simbología que desacraliza al poder político y una autorepresentación por parte del jefe del poder Ejecutivo que resalta su experiencia empresarial como garantía de eficacia y eficiencia en la administración pública.

Palabras clave: relato político; trama; ethos presidencial; Macri; repertorio simbólico; tiempo verbal; Argentina; discurso político; comunicación estratégica

\section{The Anatomy of the political story: conceptualization, functions and pieces of a strategic communication tool. The case of president Mauricio Macri (2015- 2018)}

\begin{abstract}
The current work aims to delimit, order and systematize the theoretical knowledge linked to the political story. In the first part, after going through different approaches, a conceptualization of the political story is presented. It is defined as the narrative structure used by the head of the Executive branch to provide meaning, coherence, cohesion and legitimacy to his management. Then, the functions, requirements and phases of this strategic communication tool are indicated. Then, through the first three years of the Argentine president, Mauricio Macri, the five pieces that structure a political story are specified: plot, dichotomous script, verb tense, symbolic repertoire and presidential ethos. As a conclusion, we can deduce that said governmental narrative is characterized by a plot of change, a conflict between the republic and populism, a prospective language, a symbolism that desacralizes the political power and a self-representation on the part of the head of the Executive power that highlights his experience and business success as a guarantee of effectiveness and efficiency in public administration. Keywords: Political Story; Plot; Presidential ethos; Macri; Symbolic repertoire; Verb tense; Argentina; Political speech; Strategic communication.
\end{abstract}

Sumario. 1. Introducción. 2. Las funciones. 3. El engranaje del relato político. 4. Conclusiones. 5. Bibliografía

$1 \quad$ Universidad Católica Argentina E-mail: gonzalo_sarasqueta@uca.edu.ar 
Cómo citar: Sarasqueta, G. (2020). Anatomía del relato político: conceptualización, funciones y piezas de una herramienta comunicacional estratégica. El caso del presidente Mauricio Macri (2015-2018), Política y Sociedad, 57(3), 821-841.

\section{Agradecimientos}

Este trabajo se desarrolló gracias a la colaboración de Lucía Chicatun, las correcciones de Javier Muñoz Soro y el apoyo de Lourdes Puente, Orlando D'Adamo, Virginia García Beaudoux, Samantha Olmedo y la Universidad Católica Argentina (UCA).

\section{Introducción}

Los relatos han existido desde los albores de la humanidad. Si bien en las últimas dos décadas, el marketing y, años después, la comunicación política la han revitalizado, esta herramienta comunicacional precede, incluso, a la escritura y atraviesa todas las civilizaciones y geografías. "Los relatos nos permiten imaginar la transformación de nuestras vidas así como la del mundo", sostiene Eric Selbin (2012:13). Religiones, imperios, revoluciones, guerras, tradiciones: todo acontecimiento significativo ha sido representado mediante un relato. Como asegura Gottschall (2012), somos una especie adicta a los relatos.

Esta ubicuidad del relato se debe a que la atención, la memoria y las sensaciones de los seres humanos responden mejor frente una historia que ante argumentos, datos o estadísticas. "Los relatos son altamente pedagógicos, favorecen la síntesis y el recuerdo y proporcionan un contexto a sus enseñanzas", sostiene Nuñez (2008: 29). Desde el enfoque cognitivo, las personas asimilan mejor la información confeccionada con la clásica estructura: introducción-nudo-desenlace (D'Adamo y García Beaudoux, 2012; 2013, 2016a, 2016b, 2016c). En otras palabras: las realidades que magnetizan son las que están constituidas por emociones, aspectos subjetivos y cierta inyección de ficción (Terrasa, 1991; Poletta, 2006; Simmons, 2007; Westen, 2007).

En un contexto signado por la saturación de información, la emergencia del "prosumidor" (productor y consumidor de contenidos), las agendas líquidas -los temas de interés público cada vez duran menos en la pantalla de los informativos, en las portadas de los periódicos y en las redes sociales- y la economía de la atención, es comprensible que presidentes, alcaldes o gobernadores empleen, quizás como nunca antes, el relato político para legitimar, potenciar y proyectar sus gestiones. Frente a una ciudadanía cada vez más dispersa, híperconectada y desideologizada, los relatos funcionan como atajos o heurísticos cognitivos (Kahneman, 2011). Diversos autores han calificado de distinta manera este fenómeno político: "relatocracia" (Cárcar Benito, 2016), "inflación narrativa" (Salmon, 2011), "el efecto narrativo" (Rincón, 2008), "el primado del relato (Borrat, 2000), "el giro narrativo" (Pujadas Capdevilla, 2016) o "el imperativo narrativo" (Jackson, 2002).

Ante esta vasta teoría sobre relato político, el presente trabajo pretende ordenar, precisar y sistematizar dicho concepto. El objetivo principal es elaborar una herramienta analítica capaz de capturar los significados que ponen en circulación el poder Ejecutivo. Para alcanzar esa finalidad, se postulan tres objetivos secundarios: (a) 
lograr una definición de relato político; (b) alumbrar sus funciones; y, por último, (c) determinar las piezas que conforman su engranaje. El artículo está estructurado de la siguiente forma: comienza con una breve recorrida por el estado de la cuestión para delimitar una conceptualización; continuaremos con un breve apartado donde abordaremos las competencias; en tercer lugar, utilizando como caso de estudio al presidente argentino Mauricio Macri, desagregaremos el relato en cinco variables de análisis; $\mathrm{y}$, por último, ofreceremos las conclusiones y los desafíos que aparecen para futuras investigaciones.

Para empezar, es clave despejar ciertas confusiones que habitan en la comunicación y la ciencia política. Uno de los errores más comunes es equiparar storytelling con relato político. Orlando D'Adamo y Virginia Beaudoux (2016b) señalan que el storytelling es una de las principales técnicas - proveniente del marketing publicitario- que se usa para la construcción de un relato político. Según los teóricos argentinos, el clásico spot "It's morning again in America", que utilizó Ronald Reagan en 1984 es un ejemplo nítido de storytelling. Una pieza que, entre otras, sirvió para reforzar el relato político de su gestión: América es un país próspero donde priman el orden, el esfuerzo y la meritocracia. Como se observa, la escala narrativa del storytelling es micro, mientras que la medida del relato político es macro. El primero es una parte del significado; el segundo, por el contrario, es la totalidad del significado.

Más pronunciada es la distancia entre relato y acontecimiento. Gil Calvo (2016) es contundente en esta diferenciación: el acontecimiento representa una ruptura y el relato refleja una continuidad. Este último es un encadenamiento de sucesos, envueltos mediante una coherencia que produce como resultado una linealidad, un significado extendido en el tiempo; en sentido inverso, el acontecimiento es el salto impredecible, la fractura que disloca el orden y cobra relevancia por su excepcionalidad. El relato político del gobierno argentino de Néstor Kirchner puede ser un buen ejemplo. Un acontecimiento fue cuando, el 24 de marzo de 2004, el presidente ordenó bajar el cuadro del dictador Jorge Rafael Videla del Colegio Militar. Eso fue un hecho sobresaliente que marcó la agenda pública. El relato político, en cambio, fue una linealidad de hechos que, gracias a su conexión, le permitieron transmitir un significado mayor: un gobierno comprometido con los derechos humanos que habían sido violados durante la última dictadura militar (1976-1983).

Otra distinción necesaria es entre "mito de gobierno" (Riorda, 2006) y relato político. Pedemonte (2016) identifica al "mito de gobierno" como la visión estratégica que nace en el mercado ideológico de la campaña electoral y se concreta una vez que se accede al Estado. En otra dirección, Pedemonte argumenta que "el relato es el rito del mito: su actualización, para la que se requiere una sistemática puesta en escena de la narración" (2016: 96). Entonces, podemos deducir que la función del relato es preservar la contemporaneidad de aquel mito que germinó en tiempos proselitistas. El relato no debe permitir que, frente a los cambios coyunturales, el mito se "oxide" o quede desfasado temporalmente.

Aclaradas estas distinciones conceptuales, buscaremos obtener una conceptualización. Un punto de partida es la Antigua Grecia, donde pensadores como Aristóteles (2010) y Platón (2015) ya disentían sobre su significado: el primero, en su libro "Poética", afirmó que la diégesis (relato) era una de las formas de imitación poética; el segundo, en "La República", sostiene que el relato es lo contrario a la imitación: es cuando el poeta narra un hecho en primera persona del singular, 
no simula ser otro sujeto. La discrepancia es si la voz que despliega la narración ostenta el atributo de ficción (emular a un tercero) o la facultad de reproducir solo experiencias propias.

En el siglo XX, Algirdas Greimas propuso que se considere al relato como una unidad discursiva, un algoritmo o una cadena de enunciados "cuyas funciones-predicados simulan lingüísticamente un conjunto de comportamientos que tienen una finalidad" (1966: 46). Similar es la apreciación de Genette (1966), que entiende al relato como la representación de un conjunto de acontecimientos, que pueden ser fantásticos o verdaderos, a través del lenguaje (preferentemente escrito). Hayden White (1980) visualiza en el relato a unas crónicas cargadas de un determinado sentido moral y configuradas mediante una trama.

Con un lente más funcional, Edelman (1991) razona que, según los elementos que minimicen o maximicen, los relatos son cruciales para alterar o consolidar estructuras de poder; es decir, tienen el potencial de generar tanto una sensación de inevitabilidad frente al presente como un efecto de que es posible y hasta necesario el cambio. Anthony Appiah indica que los relatos sirven para "sumergir a la gente en una sociedad particular a través de la transmisión de imágenes respecto de cómo el mundo es o debería ser" (2003 en Selbin, 2012: 44). Ryan (2004) los entiende como historias que recurren a las emociones y sentidos de las personas mediante una construcción cognitiva que diseña una imagen mental que el destinatario reproduce en su cerebro. Tilly agrega que los relatos esclarecen hechos dramáticos, asombrosos, paralizantes o enigmáticos. En este sentido, expone:

Hacen un trabajo esencial para la vida social, consolidando el compromiso de la gente con los proyectos comunes, ayudando a dar sentido a lo que ocurre, canalizando decisiones y opiniones colectivas, estimulando a la gente para una acción ante la que, de otra forma, se mostraría reacia (Tilly, 2002, en Selbin, 2012: 61)

Frank Luntz es contundente al momento de enlazar moral, relato y energía social: "No es lo que dices, es lo que la gente escucha" (2007: 267). Justamente, Salmon (2008) alerta sobre los fines inmorales que puede perseguir un relato político. El riesgo reside en su condición hipnótica: la sociedad puede ingresar en un estado de somnolencia, donde el sentido crítico quede suspendido y hechos inhumanos o crueles se asimilen con naturalidad.

Nuñez (2008) afirma que el relato es una herramienta comunicacional constituida en una serie de acontecimientos que tienen como objetivo principal activar nuestros sentidos y emociones. Según el escritor español, el fin del relato es destapar una verdad que le imprima valor a nuestra existencia. Esta perspectiva es retomada por Gutiérrez Rubí, que descifra al relato como una historia vital que "cuando transmite, evoca, comunica, emociona, moviliza, seduce, identifica, compromete y convence desde la veracidad de lo que sentimos como auténtico" (2009:28).

Por su parte, Eric Selbin ilumina la capacidad que exhibe el relato para plasmar, cristalizar y dotar identidades.

Los relatos son un depósito de perspectivas y valores, una forma a través de la cual la gente se descubre a sí misma y se asocia (o se distingue de) otra gente, y un reflejo de lo que las culturas entienden como verdadero en el pasado, el presente y futuro (2012: 44). 
Gil Calvo (2016) piensa que el relato puede hilvanar sucesos y sujetos asilados en una trama coherente. Ese adhesivo, que posee para amalgamar piezas desvinculadas en un principio, le otorga credibilidad al discurso y, al mismo tiempo, legitimidad para determinar qué acción es normal y cuál queda por fuera de los bordes de lo lógico. Desde un ángulo similar, Pujadas Capdevilla resalta que los relatos "son propuestas para dotar de significación determinados fenómenos, hechos políticos, económicos o de cualquier índole" (2016: 125).

Dos referencias en este campo teórico son los investigadores Orlando D'Adamo y Virgina García Beaudoux (2012; 2013; 2016a; 2016b; 2016c). Ellos entienden al relato político como una "novela del poder". Aseveran que, si bien la materia prima es la realidad, siempre existe una porción de ficción. Para poder activar energías sociales, es imprescindible que los hechos estén aderezados con diferentes recursos literarios: metáforas, drama, suspenso, mitos, hipérboles o antítesis.

Por su parte, definimos al relato como una estrategia de comunicación política. Como tal, sirve para transmitir valores, objetivos y construir identidades. Es una historia persuasiva que actúa a modo de "marca" de un partido, líder o gobierno. Moviliza, seduce, evoca y compromete mediante la activación de los sentidos y las emociones (D’Adamo y Beaudoux, 2016b: 25).

Luego de este breve repaso por el estado del arte, podemos elaborar una definición: el relato político es la herramienta comunicacional que le brinda significación, coherencia, cohesión y legitimidad a una gestión. Sin él, no hay un proyecto de sentido sino un inventario de políticas públicas. Las estadísticas, el lenguaje de los expertos y los datos dominan la comunicación gubernamental. Los técnicos desplazan a los políticos en la tarea de la persuasión. El repertorio de valores queda opacado por un conjunto de guarismos deshilvanados. En fin, la reputación depende de una calculadora más que de una historia.

Un relato político eficaz enciende, moviliza y, hasta incluso, cuando es necesario, paraliza el sentido social. En momentos de crisis, puede llegar a detener o minimizar contrarrelatos que atentan contra la credibilidad del gobierno. Cuando la historia es sólida puede administrar los volúmenes de la agenda pública: definir estratégicamente qué voces -partidarias, judiciales, empresariales, periodísticas, etc.- se escuchan más alto y qué voluntades se oyen bajo. La fuerza de una narrativa no solo se mide por su capilaridad social, sino también por la habilidad para desactivar los guiones de adversarios.

Es importante aclarar que no todo discurso de gobierno es un relato político. Existen determinados atributos que se deben cumplir: (I) consistencia, que se sostenga en el tiempo sin alterar la esencia del mensaje; (II) plasticidad, que sea flexible para adaptarse a los cambios de la coyuntura (capacidad de reencuadre); y hegemónico, que sea apropiado por una mayoría ciudadana y se convierta en sentido común (D`Adamo y Beaudoux, 2016c). En tiempos de autocomunicación de masas, una condición para añadir es la bidireccionalidad. Es fundamental que el relato circule en dos sentidos: desde la sociedad hacia el poder político (bottom up) y desde el poder político hacia la sociedad (top down). Para que se produzca esta interacción, es indispensable que el principal vocero del relato, el presidente, sea permeable a las corrientes de tipo ascendente. Esto le garantizará dinamismo, resignificación y 
actualidad al relato político. También es importante matizar que el relato político no circula en soledad, sino que tiene competencia. En aquellos países donde rige la democracia (libertad de expresión, pluralidad de voces, acceso a internet, etc.), el relato convive con un contrarrelato y varios microrrelatos. El contrarrelato es la narrativa alternativa, que cuenta con la fuerza suficiente para antagonizar con el relato oficial y postularse como su posible sucesor. Los microrrelatos, en cambio, son historias mínimas que carecen de potencia simbólica, tienen una recepción social acotada y no amenazan a la historia de poder que ofrece el Gobierno.

\title{
2. Las funciones
}

La bibliografía le ha asignado varias funciones al relato político. En una época marcada por la crisis de las estructuras de contención modernas (Estado, sindicatos y partidos políticos), la reconfiguración del espacio público (el campo virtual está desplazando al físico), el cambio climático y la aceleración de la robotización, el relato concibe certezas, esperanzas y expectativas. Cuando la narrativa de gobierno conecta con la energía social, se reduce el miedo a lo desconocido, la realidad recupera sus contornos y la ciudadanía puede planificar su vida. D’Adamo y García Beaudoux (2016c) utilizan la analogía de "ansiolíticos sociales" para explicar esta tarea.

Una segunda competencia es cohesionar el tejido social. El relato político puede afianzar un conjunto de valores comunes, fortalecer los patrones culturales e incentivar los lazos comunitarios. Gottschall (2012) esgrime que el relato nos homogeneiza e incentiva a comportarnos bien, $\mathrm{y}$, como consecuencia, reduce la fricción ciudadana. Además, como sostiene Nuñez (2007), el relato estimula la interactividad, la participación y la labor colectiva; es decir, trabaja en la dirección contraria al individualismo, el aislamiento y la desconfianza. El investigador Michael Jackson lo expresa así:

\begin{abstract}
Al construir, vincular y compartir historias, las personas se esfuerzan por restablecer la viabilidad de su relación con los demás, corrigiendo un sesgo hacia la autonomía cuando se ha perdido, y afirmando los ideales colectivos frente a las experiencias separadas (2002:18).
\end{abstract}

La tercera función está relacionada con la comprensión. Diariamente, los seres humanos estamos expuestos a un caos de información. Un relato eficaz nos simplifica la realidad y nos hace inteligible lo complejo. D’Adamo y García Beaudoux (2016b), usando como referencia a Kahneman (2011), consideran que los relatos son poderosos heurísticos cognitivos: condensan escenarios complicados en marcos dicotómicos fáciles de entender. Por ejemplo, la hipótesis utilizada en numerosas ocasiones por el presidente Chávez que Venezuela tiene dos caminos para elegir: el pueblo (encarnado en él) o la oligarquía (la prensa, las elites, el capital). Este recorte de la realidad evita los matices históricos, las relaciones de fuerza y otras lecturas pormenorizadas, pero permite que un amplio sector de la sociedad tenga un análisis mínimo para opinar o tomar decisiones.

La cuarta función es dinamizar voluntades: el relato político impulsa a las personas hacia la acción. Su poder es doble: produce simulación (una guía sobre cómo actuar) e inspiración (motivos para actuar) (Heath y Heath, 2007). Ambas facultades 
son esenciales para la movilización política ya que las personas necesitan instrucciones y causas para salir de su espacio privado y expresarse en la esfera pública. El relato político brinda dichos recursos, los envuelve en una trama y, además, los corporiza en personas de carne y hueso para alcanzar el impacto emocional. Como sostiene Peytibi: "Los relatos logran que transformemos datos crudos en emociones y sensaciones genuinamente personales" (2016: 167).

Consideramos oportuno sumar dos funciones. La primera: los relatos ordenan el sistema de partidos. En todo sistema democrático, donde estén garantizadas las libertades de asociación y expresión, transitan un relato, un contrarrelato y varios microrrelatos. $\mathrm{La}$ competencia partidaria es una batalla narrativa: cada fuerza compite por transformar su historia -"una sociedad meritocrática", "un país igualitario", "un pueblo solidario", etc.en sentido común. En esta disputa comunicacional se especifican y acentúan las fronteras que separan a las diferentes propuestas de poder. El menú político se estructura de manera más clara en la mente del ciudadano. Por último, en países con fragilidad institucional, como en Latinoamérica o África, el relato puede reforzar la gobernabilidad. Cuando la gestión no ofrece resultados que le mejoran la vida a la ciudadanía y la mayoría de sus variables económicas empeoran, un relato sólido puede servir para estirar la paciencia social, preservar los apoyos políticos y concluir el mandato.

\section{El engranaje del relato político}

Luego de confeccionar una definición de relato político y explicar sus funciones, continuaremos con una descripción de sus piezas: la trama, el guión dicotómico, el tiempo verbal, el repertorio simbólico y el ethos presidencial. De esta forma, se pretende operativizar el análisis de este instrumento comunicacional.

Para facilitar la comprensión, se completará el abordaje teórico con un desarrollo práctico. El corpus empírico se extraerá de los primeros tres años de la presidencia de Mauricio Macri en Argentina: 10 de diciembre de 2015 a 10 de diciembre de 2018. La justificación de dicho recorte temporal es visualizar el relato político en diferentes contextos: inmersión en las instituciones del Poder Ejecutivo (año 2016), fase proselitista (año 2017) y comunicación de crisis (año 2018). Serán discursos que el jefe del Ejecutivo brindó en diferentes ámbitos: parlamento, organismos multilaterales, canales de televisión, conferencias de prensa, spots y actos proselitistas. Esta diversidad de formatos permitirá una aproximación integral, que capture los matices que se generan en cada registro, condición indispensable para precisar el relato político del mandatario.

Es necesario aclarar que nuestro análisis se concentrará en la producción, no en el efecto social del relato político (Pedemonte, 2016; Verón, 1987 y 2003). El foco estará puesto en el enunciado y en el enunciador; las reacciones, interpretaciones o resignificaciones de los destinatarios escapan a los objetivos de este trabajo.

\subsection{La trama}

La primera dimensión analítica que analizaremos es la trama o, como la denomina Neuman (2006), línea argumental. Esta se entiende como la temática rectora que atraviesa el relato desde el principio hasta el desenlace. Mediante ella, se conectan los personajes, eventos, escenografias, temporalidades, simbologías, valores y mitos (Truby, 2010). La 
coherencia o lógica de una historia depende en gran medida de la trama. Cuanto más difusa es ella, menos consistencia ofrece el relato: las acciones se muestran aisladas, desordenadas, sin ningún patrón que las hilvane en un todo comprensible. Poletta es contundente en este aspecto: "La trama es la estructura de la historia. Sin ella, los eventos serían meras ocurrencias, momentos discontinuos y separados" (2006:9).

Para Klent las tramas son fundamentales para plasmar la identidad y trazar el vínculo estratégico con el resto de los actores sociales o políticos.

Las tramas maestras sirven como un medio para que las organizaciones cuenten su propia historia, construyan identificación y se conecten con otros. De hecho, para que las organizaciones cambien o evolucionen después de una crisis se requiere una nueva visión, un nuevo propósito, una nueva perspectiva del mundo (Ulmer et al., 2007; Veil \& Kent, 2008) y una reevaluación de los héroes organizacionales y villanos (2015: 484).

En este trabajo nos interesa el tipo de trama que se propone para ensamblar y darle sentido al relato político. Los gobernantes cuentan con un sinfín de tramas, cada una es diseñada ad hoc, de acuerdo con el entorno social, político, económico y cultural en que se encuentra la gestión. Sin embargo, a pesar de que existen tantas tramas como proyectos de poder, hay investigadores que han esbozado un catálogo básico. Heath and Heath (2007) identifican tres. La primera es la trama del desafío, donde el protagonista (en nuestro caso, el presidente) enfrenta un reto mayúsculo - "Una crisis económica", "la pobreza" o la "persecución judicial de la oligarquía"- que lo hará superarse, reinventarse y crecer. La segunda es la trama de conexión, donde la vida del personaje principal sirve de fuente inspiración para la ciudadanía. "La austeridad" (José Mujica), "el emprendedurismo" (Donald Trump) o "la tolerancia" (Nelson Mandela) serían casos de este tipo. La tercera es la trama creativa, donde el héroe descubre una supuesta solución original, inédita y única que permitirá vivir mejor a su pueblo. El "Multiculturalismo" de Evo Morales, el "Pluralismo" de Justin Trudeau y la "Tolerancia cero hacia el delito" Jair Bolsonaro podrían servir de arquetipos en esta última especie.

En sintonía con el enfoque de este trabajo, D’Adamo y García Beaudoux (2013) proponen otras tramas para fabricar un relato político. La trama del cambio que utilizó Barack Obama -durante 2008- para llegar a la Casa Blanca se distingue por la promesa de terminar con el pasado y comenzar con una nueva era repleta de esperanza, frescura y prosperidad. Otra es la trama del emancipador, donde el mandatario otorga derechos nuevos a su pueblo. Manteniendo la geografía en Estados Unidos, Lincoln con la liberación de los esclavos en la guerra civil es un prototipo de esta línea argumental. La trama reivindicativa completa la lista, que, con una fuerte impronta histórica, se destaca por la restitución de derechos, valores e identidades. Hugo Chávez fue uno de los presidentes de la izquierda latinoamericana que más empleó esta trama para estructurar su relato político. Canaleta (2010) aporta la trama del orden, que se sustenta en el enfrentamiento entre las fuerzas de la estabilidad y las del caos.

Yendo al caso de Macri, su coalición Cambiemos ${ }^{2}$ ya ofrece una pista con el nombre de su marca: una invitación a diferenciarse de las propuestas clásicas del sistema

2 La coalición Cambiemos está compuesta por tres partidos políticos: Unión Cívica Radical (UCR), Coalición Cívica (CC) y Propuesta Republicana (PRO). 
político argentino. Desde el inicio, esta alianza partidaria se posicionó como una fuerza disruptiva que, además de pretender instalar un nuevo modelo económico de sesgo liberal, apuntó a transformar el aspecto cultural de la sociedad. Así lo reflejó el mandatario en el inicio de sesiones legislativas:

Cada día, cuando llego a mi oficina, lo que pienso es qué injusticia podemos corregir, qué desigualdad podemos solucionar demostrando que es mentira que eran inevitables. Y ahí está nuestro principal problema: esa negatividad que nos ha llevado a pensar durante años que era así, que la corrupción era una forma de ser de los argentinos, que la pobreza vino para quedarse y no tiene solución. Yo hoy quiero denunciar esa visión triste, aplastante, frustrante, porque no es verdad. Todo puede cambiar y ya lo estamos cambiando (1/3/2016).

Una estrategia elemental para instalar esta trama del cambio es ubicarse como un sujeto externo a la política, sin los "vicios" de la dirigencia tradicional y dispuesto a crear una nueva manera de conducir el Estado. A pesar de haber sido alcalde de la ciudad de Buenos Aires durante dos periodos (2007-2011 y 2011-2015), Macri empleó este recurso en varias ocasiones. Un ejemplo fue en su asunción:

Aprovecho para darles un mensaje a nuestros hermanos de América y del mundo. Tenemos una visión nueva de la política. Somos hijos de este tiempo y tratamos de comprenderlo sin prejuicios ni rencores. Creemos en la unidad y la cooperación de América Latina y el mundo. Creemos en la unidad y la cooperación de América Latina y el mundo, en el fortalecimiento de la democracia como única posibilidad de resolver los problemas de sociedades diversas (10/12/2015).

El objetivo de instalarse como un dispositivo de poder inédito ha sido tan intenso que, en momentos sensibles de la gestión, como en el 2018, cuando se acudió al Fondo Monetario Internacional (FMI) para pedir un préstamo extraordinario, Macri mantuvo la fidelidad a esta trama. En plena comunicación de crisis, el presidente -en un vídeo para las redes sociales- lo manifestó de la siguiente manera:

Estamos haciendo todo lo que está a nuestro alcance para salir adelante. Estoy convencido, más que nunca, que juntos vamos a conseguir superar nuestras dificultades. Cambiando de verdad, de raíz. Y entendiendo que no hay atajos mágicos $(29 / 8 / 2018)$.

Como muestran estos pasajes discursivos, Macri escogió la trama del cambio. Una línea argumental que descansa sobre tres pilares: la puesta en práctica de una nueva cultura política por parte de los dirigentes que conducen la gestión, la sustitución del pesimismo por el optimismo en la idiosincrasia argentina y el diálogo como vector central de la democracia. El corte radical con el pasado es el valor principal que le imprime al relato político. Claro que para concebir este salto temporal como positivo y necesario, existe una apreciación política previa: la historia reciente, es decir, los doce años del kirchnerismo en el poder, presenta un balance negativo. 


\subsection{El guión dicotómico}

La tensión narrativa de cualquier relato político se sostiene mediante el conflicto. Sin él, no hay suspenso, atención ni interés. La ciudadanía necesita visualizar en la arena pública dos respuestas tentativas a sus problemas: el protagonista (el presidente) y al antagonista (líder opositor). Ambos encarnan una disputa simbólica, valórica e ideológica que desata un cúmulo de incertidumbres, desequilibrios e inseguridades en el tejido social. Cuanto más abierto esté el desenlace de esta lucha, más intenso será el involucramiento de las personas. Para no perder el interés de la sociedad, el mandatario deberá regular-de acuerdo al contexto, fomentar o atenuar-el enfrentamiento con su adversario.

En esta dirección, el ensayista Omar Rincón (2008) se refiere al carácter dramático que debe almacenar todo relato político para ser eficaz. La lógica tiene que ser combativa contra los contradictores, aquellos que, con un contrarrelato, intentarán deconstruir la historia de poder que produce el gobierno. Esa instancia de riesgo que genera el opositor, a la cual Barthes (1966) llama "función cardinal", debe ser utilizada estratégicamente por el presidente. A esta necesidad de contar con un oponente, un sujeto que persiga la misma meta -el progreso del país-, pero con otro método, la vamos a denominar guión dicotómico. Este esquema binario, que una amplia gama de investigadores considera imprescindible en cualquier narrativa de poder (D'Adamo y Virginia García Beaudoux, 2012; 2013, 2016a, 2016b, 2016c; Jackson, 2002; Borrat, 2000; Truby; 2010; Canaleta, 2010; Klent, 2015; Pedemonte, 2016; Pujadas Capdevilla, 2016), le permite al líder moldear la identidad de su espacio. Al dotar de un conjunto de atributos negativos al contrincante, se produce una autoidentificación automática: somos todo aquello que no es nuestro competidor. Murray Edelman lo explica de este modo:

En política, los antagonistas también ayudan a constituir la subjetividad. Las personas politizadas se definen en gran medida en los términos de su oposición a los otros grupos que temen y condenan. Es especialmente probable que los líderes y los aspirantes al liderazgo se construyan una imagen sobre la base de la oposición a un enemigo o grupo de enemigos (1991: 85).

De las tres formas de identificación que destaca Burke (1969a), por simpatía, desconocimiento o antítesis, el guión dicotómico cuadra con la tercera. El relato defiende un repertorio positivo de valores y, al mismo tiempo, identifica un repertorio negativo de valores para atacar. El primero está dedicado a lo que Eliseo Verón (1987) denomina "prodestinatario", el destinatario positivo que adhiere a los mismos códigos morales, estéticos, y culturales; el segundo, en cambio, está dirigido al "contradestinatario", el destinatario negativo que representa los códigos morales, estéticos y culturales contrarios a los del relato oficial.

Como observamos, Mauricio Macri despliega una trama del cambio ${ }^{3}$, basada en la distinción entre el pasado y el futuro. Ahora, se trata de avanzar al siguiente nivel

Saúl Feldman (2019) plantea que dicha trama del cambio, en realidad, significa el regreso del neoliberalismo a la Argentina. Después de la experiencia de Carlos Menem en los años noventa, la gestión de Mauricio Macri retoma una cosmovisión marcada por la desregulación financiera, el libre mercado y la retirada del Estado de sectores estratégicos de la economía. El diferencial respecto a los gobiernos de Menem reside en la estrategia comunicacional, en donde Cambiemos combinó y aplicó recursos del marketing político, las ciencias políticas, la sociología, la ingeniería digital y la teología. 
análisis del relato y descubrir cómo se traduce esa línea argumental en un juego dicotómico entre actores políticos. En una entrevista al programa televisivo "Periodismo para todos", Mauricio Macri trazó la siguiente comparación implícita con los mandatos de Néstor Kirchner y Cristina Fernández:

El mundo compró una Argentina que se alejaba del modelo Venezuela para ir a un modelo de inclusión, moderna, de la gente, del trabajo, del crecimiento, del desarrollo. Respetando reglas, no diciendo que voy a jugar el mundial de fútbol con 14 jugadores, como hacía el gobierno anterior. Yo invento de vuelta las reglas del mundo. No, nosotros somos uno más (17/06/2018).

Como se contempla, Macri establece una dicotomía tácita: utiliza el significante Venezuela para activar el marco conceptual del populismo, cuya mímesis en Argentina es el kirchnerismo. Intenta instalar en la mente de su prodestinatario el guión binario de manera indirecta, sin nombrar explícitamente al gobierno predecesor. Durante un acto en la Sociedad de las Américas, donde recibió el máximo galardón de la institución, el líder de Cambiemos ahondó en esta crítica hacia el populismo:

"El populismo es como ir a una fiesta en la que te emborrachan con todo el alcohol posible. Puede ser divertido, pero a la mañana siguiente a uno le explota la cabeza" 7/11/2017).

"Cuando termina, el populismo deja la sociedad quebrada, sin patrimonio, sin infraestructura y tiene que empezar casi de cero" 7/11/2017).

En un contexto de crisis económica, como el que atravesó la gestión de Cambiemos en 2018, donde hubo inflación, devaluación del peso frente al dólar e incremento de la pobreza, Macri enfatizó esta dicotomía. Pero a diferencia de las anteriores piezas, en este discurso nombró a su adversaria, Cristina Fernández. En un comunicado, donde informó que subían precios de los servicios básicos, recurrió a una confrontación abierta, precisa y explícita con la ex presidenta.

Por eso les pido a los senadores que demuestren que existe un peronismo responsable y confiable, que no se deja conducir por las locuras que impulsa Cristina Fernández de Kirchner. Confío que van a actuar de manera racional porque la etapa del despilfarro se terminó (28/5/2018).

Como demuestra este segmento, Macri genera una equivalencia entre desmesura y Cristina Fernández. A su vez, intenta trazar una división en el seno del peronismo, entre el sector responsable, interpretado por los gobernadores del interior del país y el centrista Frente Renovador, y la rama populista, representada por el kirchnerismo. Resumiendo, Mauricio Macri utiliza un guión dicotómico contra el kirchnerismo para promover su proyecto político. Según el presidente argentino, la fuerza que fundó Néstor Kirchner reproduce el populismo regional en el país. El repertorio de valores negativos que Macri le adosa a este movimiento incluye la insensatez, la 
corrupción, la prepotencia y la demagogia. Como respuesta, su fuerza Cambiemos vendría a proponer una lista de valores positivos: la sinceridad, la transparencia, la legalidad y el desarrollismo. Esta lógica binaria diseñada contra el kirchnerismo complementa la trama del cambio que definimos anteriormente: el pasado de Argentina es el populismo kirchnerista; el futuro, el republicanismo de Cambiemos.

\subsection{El tiempo verbal}

D’Adamo y García Beaudoux (2016b) afirman que los relatos políticos tienen una estructura temporal, un hilo que ordena cronológicamente el discurso. Greimas expresa que el relato cuenta con una dimensión temporal, esto quiere decir "los comportamientos que expone mantienen entre sí relaciones de anterioridad y de posterioridad" (1966: 46). Nuñez (2007) amplía y sostiene que el relato incluye todas las fases temporales: pasado, presente y futuro. Los tres tiempos verbales, según la estrategia comunicacional y los momentos de la gestión, se alternan en la producción discursiva de un presidente. "Un relato no es más que explicar de dónde venís, donde estás y adónde vas”, determina Pau Canaleta (2010: 137).

Más allá de estar de acuerdo con la bibliografía en que las tres fases temporales habitan -con mayor o menor intensidad- en todo relato gubernamental, en este trabajo nos interesa precisar el tiempo verbal que predomina. En otras palabras: vislumbrar si estamos frente a un relato político de orden reivindicativo (pasado), cotidiano (presente) o aspiracional (futuro). El relato reivindicativo se concentra en la memoria colectiva, en cuál ha sido la historia que nos condujo a este presente, en cómo se forjó la identidad de una nación: revisa la fuente cultural que compartimos para unir o dividir estratégicamente a la sociedad. Es común que esté cargado de idealizaciones, romanticismo y épica, y su objetivo es fundar una analogía entre el actual gobierno y experiencias trascendentales en el imaginario social. En cambio, el relato cotidiano está vinculado a lo que sucede diariamente en la gestión. Se emplea para explicar una política pública, una disputa o una crisis. Debido a los límites que dicta el contexto, su tono es más racional, técnico y calculado, y su fin es transmitir la agenda de gobierno. El relato aspiracional promete un destino, dibuja horizontes de bienestar, marca el rumbo de la nación. Está hecho de optimismo y creatividad y su función es fabricar expectativas -tanto individuales como grupales- que justifiquen determinados esfuerzos o sacrificios del presente.

De los tres niveles temporales, el relato cotidiano es el que está más expuesto al control ciudadano. El contraste entre hechos y narrativa está al alcance de estadísticas, investigaciones periodísticas o informes de fuerzas opositoras. Esta es una de las razones por las cuales la mayoría de los relatos políticos son reivindicativos o aspiracionales. Como argumenta Jonathan Gottschall (2012), el pasado y el futuro son simulaciones mentales, fantasías que se producen en nuestro cerebro; por ende, son más difíciles de testear que aquellas narrativas referidas al presente. Por esta razón, John Truby (2010) se refiere a "la falacia del pasado" y "la falacia del futuro".

En el caso de Macri, ya en su discurso de asunción podemos detectar dónde se inscribe temporalmente su relato político.

La entrada al siglo XXI, que la Argentina en cierto sentido ha retrasado, es una gran responsabilidad de este gobierno y es un motivo de gran excitación, de gran entusiasmo. Invitamos a todos a sumarse a esta apasionante tarea de ser pioneros 
de un mundo nuevo. Queremos que la Argentina entre en el siglo XXI incorporando políticas de gobierno abierto. Esconder y mentir sobre nuestra realidad es una práctica que nos ha hecho mucho, mucho daño (10/12/2015).

El ingreso del país al siglo XXI es una tarea de la gestión de Macri. El mensaje subterráneo es que, a pesar de haber transcurrido quince años del nuevo siglo, Argentina aun permanece en el siglo XX, atrapada en los problemas del pasado. La transparencia institucional, la rendición de cuentas y la información pública son cuentas pendientes que ninguno de los presidentes anteriores -De la Rúa, Duhalde, Kirchner y Fernández- ha podido resolver. Él, por el contrario, ha llegado para concretar este desafío, culminar el proceso de modernización e instalar a la nación en el futuro. Dicha labor, según el presidente, exige tiempo.

Nuestro compromiso con el cambio es serio. Y tanto que aún sabiendo que es un largo camino, donde nadie nos va a regalar nada. Lo vamos a seguir recorriendo juntos. ¿Y saben por qué? Porque aspiramos a más, a vivir mejor, a tener proyectos, sueños y llevarlos a cabo" (22/10/2017)

Esta pieza discursiva, además de subrayar la trama del cambio, muestra claramente el lenguaje aspiracional. Macri confirma sus deseos de progreso, crecimiento y evolución. Este tipo de enunciados motivacionales fueron una constante en sus intervenciones públicas. A continuación, otro ejemplo donde prevalece el optimismo sobre el futuro:

Por eso, nuevamente los invito al entusiasmo del hacer, a la alegría de sentirse comprometidos, de sentirse protagonistas de su propio futuro, al orgullo de pertenecer a la generación que está cambiando a la Argentina para siempre (1/3/2018)

La diferencia de esta alocución con las anteriores es que resalta la responsabilidad individual de cada ciudadano. Subyace la impronta liberal: cada persona tiene el poder de decidir -más allá de sus condiciones sociales, culturales y económicas de origen- sobre su propio destino. El tiempo verbal, sin embargo, continúa siendo el futuro. Al igual que en los extractos anteriores, el pasado está ausente y el presente solo figura como espacio de transición. En conclusión, Macri impulsó claramente un relato político aspiracional. Las expectativas, la modernización, la responsabilidad y la globalización fueron los tópicos que consolidaron esta narrativa prospectiva. De esta manera, reforzó su trama del cambio y acentuó la lógica dicotómica contra el kirchnerismo, fuerza que, en sentido contrario, con su defensa de los derechos humanos y la militancia juvenil de los años setenta, propuso una lógica reivindicativa.

\subsection{Repertorio simbólico}

Los símbolos son clave en cualquier relato político. Su capacidad metafórica y simplificadora permite comprender, significar o sintetizar el relato gubernamental. A diferencia de la argumentación, que exige tiempo, atención y reflexión, los símbolos son instantáneos, directos y emocionales. Para O'Sullivan (et. al), un símbolo "es 
un signo, un objeto o un acto que hace las veces de algo diferente de sí mismo" (1995:330), y que funciona gracias al acuerdo existente entre miembros de una cultura determinada. Truby (2010) añade que el símbolo es un significado altamente concentrado. Según D`Adamo y Beaudoux, los símbolos son esenciales en un relato político porque facilitan la comunicación de los mensajes.

La utilización de símbolos en la comunicación gubernamental ayuda a desactivar razonamientos críticos, a la vez que transmitir conceptos complejos de un modo simple: la balanza de la justicia, las cadenas rotas de la libertad o la $\mathrm{V}$ de la victoria son símbolos rápida y fácilmente comprensibles por todos (2016b: 201).

Cada gobierno cuenta con un repertorio simbólico que incluye gestos, monumentos, imágenes, banderas y escenarios. Cuando Cristina Fernández realizaba una cadena nacional en televisión con la gigantografía de Eva Perón que reviste el Ministerio de Desarrollo Social de la Nación de fondo, estaba desplegando su mensaje en dos niveles: el verbal que hacía hincapié en una política pública específica y el simbólico que subrayaba el lazo histórico entre su gestión y el peronismo. En cuanto Macri, el repertorio simbólico se puede analizar desde varias perspectivas. Un variable es el dispositivo que emplea para transmitir sus mensajes. Mientras que su predecesora, en línea con la comunicación de masas del siglo XX, usaba la Televisión Pública, Macri eligió la plataforma Youtube. Este medio, nuclear en la autocomunicación de masas, pretende exhibir a un presidente actualizado tecnológica y comunicacionalmente. En estas exposiciones, que, de acuerdo con la inmediatez de las redes sociales, se caracterizan por su brevedad, el presidente se expone con una estética minimalista: camisa y saco, pero sin corbata; colores sobrios (celeste o azul oscuro); ausencia de signos políticos o imágenes de próceres; $\mathrm{y}$, a veces, cuando el comunicado es excepcional, como el pedido de préstamo al FMI citado anteriormente, lo acompaña la bandera nacional.

A su vez, una de las principales tácticas comunicacionales de Macri es el "timbreo", que básicamente consiste en la visita por parte del presidente a la casa de un ciudadano. En estos encuentros, el mandatario -vestido con una camisa o camiseta de cuello redondo- se sienta en la mesa de la cocina del anfitrión, toma mate, acepta comida casera y escucha las demandas del vecino. Desaparecen los protocolos presidenciales, se difumina la distancia entre la máxima autoridad del país y, por ejemplo, un trabajador de fábrica, produciendo una simetría (momentánea y ficticia) entre ambos. Este tipo de escenarios transforma al presidente en un ciudadano más, despojado de poder y épica, al alcance de cualquier habitante. Una simbología que cuadra con la modalidad dialógica y horizontal de las redes sociales.

Durante los actos políticos, Macri prolonga esta veta descontracturada. En el festejo por el triunfo de las elecciones legislativas de 2017, el presidente se presentó en jean, zapatillas y camisa celeste; globos, música pop, pantallas led de gran tamaño y papelitos de colores completaron la estética. Esta propuesta desdramatizada de la función pública ${ }^{4}$ se ajusta a una trama que, como vimos, apunta a diferenciarse de la clase dirigente tradicional. Si el conflicto, la ideologización y la recuperación de

4 Mario Riorda (2016) afirma que, lejos de ser un recurso o un complemento, este estilo descontracturado fue el eje comunicacional en el inicio de la gestión de Cambiemos. Todo el sistema discursivo orbitaba alrededor 
momentos históricos convulsos en Argentina, como los años setenta, fueron la fuente de donde el kirchnerismo forjó su catálogo simbólico, Macri -en dirección opuestarecurre a una lógica distendida. Todos los elementos simbólicos que emplea -vestimenta, escenarios, dispositivos, música, signos, etc.-, como así también los que deja de usar, apuntan a tonificar ese contraste con la política "clásica" del país.

\subsection{El ethos presidencial}

El presidente es el principal vocero del relato político. La función comunicacional del jefe del Ejecutivo es corporizar la propuesta de sentido que ofrece la novela gubernamental. Como argumenta Omar Rincón, los atributos personales del gobernante son los que determinan la verosimilitud del relato (2017). Cuando estas dos narrativas están conectadas, se produce un círculo virtuoso: a medida que el relato subjetivo del primer mandatario gana credibilidad, el relato gubernamental aumenta su consistencia. Si esta sinergia de significados está enlazada con las necesidades de la coyuntura, es probable que el relato político sea apropiado por una mayoría social.

En una época marcada por la personalización de la política, donde el público se concentra más en los rasgos personales que en las ideologías y los partidos políticos, el jefe de Estado se convierte en la principal caja de resonancia del gobierno, el dador del relato, el protagonista de la historia. Debido a esta mixtura entre relato personal y relato gubernamental, es común que el presidente utilice un lenguaje personal, sencillo y humano para activar las emociones de sus destinatarios (Luntz, 2007). Además, para facilitar esta empatía social, también es importante que el carisma sea acompañado por recuerdos, experiencias, intimidades y deseos (Salmon, 2011). Soledad Montero, citando a Aristóteles, define al ethos "como la imagen que el orador construye de sí mismo en su discurso" (2010:121). Es la autorepresentación que hace el presidente para insertarse en el debate público. A través del ethos presidencial podremos diferenciar el plano concreto (historia del presidente) del plano abstracto (relato político).

En Macri, desde su discurso de asunción, encontramos claramente la construcción de un ethos vinculado al mundo empresarial. Dentro de este cosmos, el presidente resalta a menudo la capacidad de crear equipos, el espíritu emprendedor y la eficiencia, todos rasgos positivos que, supuestamente, incorporó en su experiencia como hombre de negocios 5 .

A lo largo de mi vida, en el ámbito del deporte, en los ocho años que tuve el honor de conducir el gobierno de la Ciudad de Buenos Aires pude armar buenos equipos que construyeron soluciones concretas para los problemas de la gente. En este nuevo desafío, para hacer los cambios a los que nos comprometimos, necesitamos armar equipos diversos, sumar visiones distintas de nuestra realidad (10/12/2015)

de esa lógica relajada de la política, que comenzó en la fase electoral y continuó en la fase gubernamental sin cambios significativos.

5 En su libro "La larga marcha de Cambiemos" (2017), Gabriel Vommaro subraya que, después de la crisis política y económica del 2001, las elites empresariales argentinas decidieron ingresar a la función pública para resolver la cuestión social. Según el autor, en esos años es que nace el proyecto de poder político de lo que después se conocería como PRO. 
En su primera visita como máximo mandatario al principal coloquio del sector privado del país, Instituto para el Desarrollo Empresarial de la Argentina (IDEA), Macri aprovechó su pasado como inversor para pedirles esfuerzo, inversiones y compromiso a sus antiguos socios. Quiso utilizar su trayectoria profesional para generar una complicidad entre pares que facilitara su proyecto económico. No era un político reclamándole al sector privado, sino un empresario dialogando con colegas.

Esta es la casa de todos. Entonces, no depende de un presidente. No depende de su gobierno. Depende de lo que hacemos cada uno de los argentinos. Cada uno somos valiosos. Cada uno tenemos algo que aportar. Pero ustedes, muchísimo más. Ustedes tienen talento. Ustedes tienen capacidad de crear; capacidad de generar riqueza. A partir de ahí, uno puede pensar en distribuir. Un Estado al servicio de la gente. Por eso, les pido, en nombre de todos los argentinos, compromiso, entusiasmo, ganas, de demostrar de lo que vale en la vida es la superación, el esfuerzo personal. Eso es lo que te dignifica (12/10/2016)

Este recurso de capitalizar políticamente su pasado como empresario también lo usó en reiteradas ocasiones de forma explícita. Un ejemplo fue en el Encuentro Empresarial España-Argentina, donde el presidente usó su carrera profesional para empatizar con actores privados de otro país e incentivar las inversiones en el país.

Por eso, estamos trabajando en mejorar nuestra institucionalidad todos los días. En fijar reglas de juego bien claras para que ustedes, que son muy bienvenidos, puedan venir a invertir. No solo a disfrutar de nuestra compañía, porque, claramente, no hay nada más lindo en la vida, viniendo yo del mundo de los negocios, que encima que uno va y hace inversiones en un lugar, poder disfrutar en el lugar que le toca visitar (10/4/2018).

Como se advierte en estos extractos discursivos, el presidente modela un ethos presidencial en torno a su historia empresarial. El objetivo de la construcción de esta imagen es imprimirle al Estado argentino rasgos que están asociados al sector privado: productividad, inversión, modernidad, agilidad y eficiencia. Otros mandatarios latinoamericanos, como Sebastián Piñera en Chile y Pedro Pablo Kuczynski en Perú, han intentado proyectar el mismo ethos de presidente-empresario. Esta autorepresentación apuntala la trama del cambio: por primera vez, un empresario alcanza la máxima investidura en Argentina. Esta supuesta conciliación de lo privado con lo público subraya el guión dicotómico con el kirchnerismo, cuyo relato -en sentido inverso- apuntaba al enfrentamiento del Estado contra los grandes poderes económicos. A su vez, el ethos de presidente-empresario empalma con el repertorio simbólico desdramatizado, festivo y desprovisto de signos políticos y contenido histórico. Por último, el lenguaje aspiracional conjuga con el atributo innovador que él mismo le endosa al sector empresarial.

\section{Conclusiones}

El objetivo cardinal de este trabajo era producir una herramienta analítica capaz de abordar los significados que producen los gobiernos. Para alcanzar esa meta, primero se hizo un repaso por el estado de la cuestión y luego se definió al relato político 
como una estrategia comunicacional que emplea el jefe del ejecutivo para brindarle significación, coherencia, cohesión y legitimidad a su gestión. Como siguiente paso, se presentaron las funciones que cumple el relato político: en un contexto saturado de información, simplifica la realidad; facilita la cohesión social, es decir produce un "nosotros"; genera certezas en un ambiente caracterizado por el cambio constante; dinamiza voluntades para un determinado fin político; ordena los diferentes sentidos que circulan en un sistema de partidos; $y$, en países, con experiencias institucionales traumáticas, puede ser un factor más para conservar la gobernabilidad.

Para operativizar su análisis, como tercera tarea, se desagregó al relato político en cinco piezas: el guión dicotómico, el tiempo verbal, el repertorio simbólico y el ethos presidencial. Para completar esa labor teórica y facilitar la comprensión, se utilizaron como corpus empírico extractos discursivos del presidente Macri durante sus primeros tres años de gestión. El resultado arrojó que el relato político del mandatario argentino contiene una trama del cambio, se sostiene en la dicotomía república-populismo, se expresa mediante un lenguaje aspiracional, se presenta con un repertorio simbólico desdramatizado y es reforzado por un ethos de presidenteempresario.

Este relato político le permitió a Macri transformar las elecciones de 2017 en una fase expansiva y convertir la crisis de 2018 en una fase de contención. Cuando la coyuntura - descenso de la pobreza, expectativas económicas, respuestas positivas de los mercados mundiales, etc.- conectó con su relato político, como en el 2017, Macri incrementó el respaldo social. El cambio, la libertad y la república fueron la materia prima discursiva con la que Cambiemos estructuró su relato político, conformó su segundo anillo social y aumentó su músculo legislativo a nivel nacional. En este caso, las piezas que más se emplearon fueron el ethos de presidente-empresario de Macri, como síntesis de la Argentina moderna que se proponía, y el lenguaje aspiracional, para generar optimismo y expectativas en la ciudadanía sobre el futuro.

En caso contrario, cuando el contexto fue adverso, como con las crisis cambiarias y la recesión económica de 2018, el relato político ayudó a conservar el primer anillo social de Cambiemos. Según los estudios demoscópicos, hacia fines de 2018, el gobierno nacional contaba con un piso social del $30 \%$. Ese núcleo duro se explica por el temor a un "regreso populista", no por el bienestar, el progreso o las mejoras en las condiciones de vida. Es un apoyo que se sustentaba más en la imagen negativa de la ex mandataria Fernández que en la imagen positiva de Macri. Sin duda, en esta etapa, se intensificó el uso del guión dicotómico y la trama del cambio, dos piezas clave para activar la identificación por antítesis (Burke, 1969a).

Diversas inquietudes surgen para futuras investigaciones. Una deuda es invertir el enfoque y, en vez de concentrar el trabajo en la producción, apuntar a la recepción social del relato político. ¿Cómo se (re)significa el relato a través de las nuevas herramientas 2.0? ¿Cómo se reconfigura la narrativa gubernamental con la participación ciudadana? ¿Qué papel juegan los medios de comunicación tradicionales en esta interacción? Responder a estos interrogantes, sin duda, generaría importantes contribuciones a la bibliografía. Otra ángulo de análisis podría ser la profundización de las distintas fases que atraviesa un relato político: nacimiento, consolidación y deterioro. Orlando D`Adamo y Virginia Beaudoux (2016b) han dado los primeros pasos en este sentido. Y, por último, sería interesante ampliar el campo de estudio y observar la formación del contrarrelato político que forja la oposición en simultáneo al relato político y, a su vez, los microrrelatos políticos que circulan en el sistema de 
partidos. Sin duda, estos aportes lograrían una radiografía más completa de la disputa de sentido que se libra en todo sistema democrático.

\section{Bibliografía}

Appiah, K. (2003): Thinking it through: An introduction to contemporary philosophy, New York, Oxford University Press.

Aristóteles (2010): Poética, Buenos Aires, Ediciones Libertador.

Barthes, R. (1966): "Introducción al análisis estructural de los relatos", en R. Barthes et al., Análisis estructural del relato, Buenos Aires, Editorial Tiempo Contemporáneo, pp.9-43.

Borrat, H. (2000): "El primado del relato", Revista Análisis, 25, pp. 41-60.

Canaleta, P. (2010): Explica't amb una historia, Barcelona, Editorial de la Universitat Oberta de Catalunya.

Burke, K. (1969a). A rhetoric of motives. Berkeley, University of California Press.

Carcar Benito, J. (2016): "Una aproximación al transmedia, el storytelling y los nuevos modelos narrativos electorales en la comunicación política actual", Revista MARCO, 2, pp. 89-110.

D’Adamo, O. y García Beaudoux, V. (2012): “El relato político”, Más poder local, 9, pp. 32-33.

D’Adamo, O. y García Beaudoux, V. (2013): “Storytelling y comunicación política: el valor de un relato bien contado", en I. Crespo y J. Del Rey, eds., Comunicación Política \& Campañas electorales en América Latina, Buenos Aires, Editorial Biblos, pp.55-69.

D’Adamo, O. y García Beaudoux, V. (2016a): “Campaña negativa. Análisis de los spots televisivos de siete elecciones presidenciales argentinas (1983-2011)", en J. del Rey Morató, A. Campillo y Y. Guan, eds., Campañas electorales en América Latina, España y Portugal, Madrid, Fragua, pp.35-45

D’Adamo, O. Y García Beaudoux, V. (2016b): “Comunicación Política: narración de historias, construcción de relatos políticos y persuasión", Revista Comunicación y Hombre, 12, pp.33-36.

D’Adamo, O. y García Beaudoux, V. (2016c): "Doce ingredientes para la construcción de un regato de gobierno.”, en E. Richard y A. González, eds., Manual de Comunicación de Gobierno, Bogotá, Universidad Externado de Colombia, pp. 195-2010.

Edelman, M. (1991): La construcción del espectáculo político, Buenos Aires, Ediciones Manantial.

Feldman, S. (2019): La conquista del sentido común. Cómo planificó el macrismo el cambio cultural, Buenos Aires, Ediciones Continente.

Genette, G. (1966): "Fronteras del relato" en R. Barthes et al., Análisis estructural del relato, Buenos Aires, Editorial Tiempo Contemporáneo, pp.193-208.

Gil Calvo, E. (2016): "El nuevo triángulo retórico: relato, encuadre y acontecimiento", en C. Colino et al., Ciencia Política, una aventura vital. Libro homenaje a Ramón Cotarela, Valencia, Tirant Lo Blanch, pp. 646-668.

Greimas A. (1966): "Elementos para una teoría de la interpretación del relato mítico", en R. Barthes et al., Análisis estructural del relato, Buenos Aires, Editorial Tiempo Contemporáneo, pp.45-86.

Gottschall, J. (2012): The storytelling animal. How stories make us human, Boston, Houghton Mifflin Harcourt.

Gutiérrez Rubí, A. (2009): Micropolítica. Ideas para cambiar la comunicación política. Disponible en web: https://www.gutierrez-rubi.es/autor/libros-2/ 
Heath C. y Heath, D. (2007): Made to stick: why some ideas survive and others die, New York, Random House.

Jackson, M. (2002): The politics of storytelling: Violence, Transgression and Intersubjectivity, Copenhagen, Museum Tusculanum Press.

Kahneman, D. (2011): Life as a Stroy. Thinking, fast and slow, New York, Digital. Farrar, Straus and Giroux.

Klent, M. (2015): "The power of storytelling in public relations: Introducing the 20 master plots", Public Relations Review, 41 (4), pp. 480-489.

López-Hermida-Russo, A. y Vargas-Monardes, J. (2013): “La política relatada: el storytelling de Barack Obama en el marco de la operación Gerónimo”, Revista Palabra Clave, 16 (1), pp.12-44.

Luntz, F. (2007): Words that work. It's Not What You Say, It's What People Hear, New York, Hyperion ebook.

Macri, M. (2015): Palabras del Presidente de la Nación, Mauricio Macri, ante la Asamblea Legislativa en el Congreso de la Nación. Disponible en web:

https://www.casarosada.gob.ar/informacion/discursos/35023-palabras-del-presidente-de-lanacion-mauricio-macri-ante-la-asamblea-legislativa-en-el-congreso-de-la-nacion

[Consulta: 14 de enero de 2019]

Macri, M. (2016): Palabras del presidente Mauricio Macri en la apertura de sesiones ordinarias del congreso. Disponible en web: https://www.casarosada.gob.ar/informacion/ discursos/35651-palabras-del-presidente-mauricio-macri-en-la-134-apertura-desesiones-ordinarias-del-congreso

[Consulta: 14 de enero de 2019]

Macri, M. (2016): Palabras del presidente Macri en el $52^{\circ}$ coloquio anual de IDEA, en Mar del Plata. Disponible en web https://www.casarosada.gob.ar/informacion/ discursos/40742-palabras-del-presidente-macri-en-el-52-coloquio-anual-de-idea-enmar-del-plata [Consulta: 21 de enero de 2019]

Macri, M. (2017). Discurso en el Consejo de las Américas. Disponible en web:

https://info135.com.ar/2017/11/08/macri-sobre-el-populismo-es-como-ir-a-una-fiesta-en-laque-te-emborrachan-con-todo-el-alcohol-posible/ [Consulta: 18 de enero de 2019]

Macri, M. en Diario La Nación (2017): Mauricio Macri, tras el contundente triunfo de Cambiemos: "Somos la generación que está cambiando la historia. Disponible en web:

https://www.lanacion.com.ar/politica/mauricio-macri-nid2074724 [Consulta: 21 de enero de 2019]

Macri, M. (2018). Palabras del presidente Macri en el Encuentro Empresarial EspañaArgentina. Disponible en web: https://www.youtube.com/watch?v=Pyv9FuD9xbo

[Consulta: 21 de enero de 2019]

Macri, M. (2018): Mensaje del presidente Mauricio Macri en la apertura del $136^{\circ}$ período de sesiones ordinarias del Congreso. Disponible en web: https://www.casarosada.gob. ar/informacion/discursos/42114-mensaje-del-presidente-mauricio-macri-en-la-aperturadel-136-periodo-de-sesiones-ordinarias-del-congreso

[Consulta: 21 de enero de 2019]

Macri, M. (2018): Mensaje del presidente Mauricio Macri. Disponible en web:

https://www.casarosada.gob.ar/informacion/discursos/43510-mensaje-del-presidentemauricio-macri [Consulta: 15 de enero de 2019]

Macri, M. (2018). Entrevista en el programa Periodismo para todos, Canal 13. Disponible en web: https://www.youtube.com/watch?v=3HXXL0SXd84 [Consulta: 15 de enero de 2019] 
Macri, M. (2018). Mensaje del presidente Mauricio Macri tras la reunión de coordinación de Gobierno. Disponible en web: https:/www.casarosada.gob.ar/informacion/ discursos/42818-mensaje-del-presidente-mauricio-macri-tras-la-reunion-decoordinacion-de-gobierno [Consulta: 18 de enero de 2019]

Montero, S. (2015): "El joven militante y el viejo sabio. Relatos sobre el pasado reciente y ethos discursivo en Néstor Kirchner (Argentina, 2003-2007) y José Mujica (2010-2015)", Revista Uruguaya de Ciencia Política, 24 (2), pp.121-137.

Neuman, W. L. (2006): Social Research Methods. Qualitative and quantitative approaches, Boston, Allyn and Bacon.

Nuñez, A (2007): ¡Será mejor que lo cuentes! Barcelona, Empresa activa.

O'Sullivan, T. et al. (1995): Conceptos clave en comunicación y estudios culturales, Madrid, Amorrortu.

Pedemonte, D. (2016): "Matices de un relato con pocos matices: comunicación gubernamental en los gobiernos kirchneristas", en M. Riorda y O. Rincón, eds., Comunicación gubernamental en acción. Narrativas presidenciales y mitos de gobierno, Buenos Aires, Editorial Biblos, pp.93-109.

Peytibi, X. (2016): "Videopolítica: de la televisión de Rosser a la generación Youtube", en R. Sánchez Medero, ed., Comunicación Política: nuevas dinámicas y ciudadanía permanente, Madrid, Tecnos, pp.149-174.

Platón (2015): La República, Madrid, Mestas Ediciones.

Poletta, F. (2006): It Was Like a Fever: Storytelling in Protest and Politics, Chicago: The University of Chicago Press.

Pujadas Capdevilla, E. (2016): "Las claves del storytelling político. El caso de la política pop”, en R. Sánchez Medero, ed.,Comunicación política: nuevas dinámicas y ciudadanía permanente, Madrid, Tecnos, pp.123-147.

Rincón, O. (2008): "De celebrities pero motivadores, pero tele-presidentes pero... ¿democracia?” en O. Rincón, ed., Los tele-presidentes: cerca del pueblo, lejos de la democracia, Bogotá, Fundación Friedrich Ebert, pp. 149-171.

Rincón, O. (2017): “Prólogo", en O. Rincón y M. Ponce, eds., Medios de lucha. Comunicación de Gobierno en América Latina, Montevideo, Penguin Random House, pp.4-7.

Riorda, M. (2006): "Hacia un modelo de comunicación gubernamental para el consenso", en D. Pedemonte, L. Elizalde y M. Riorda, eds., La construcción del consenso. Gestión de la comunicación gubernamental, Buenos Aires, Editorial La Crujía, pp.14-93.

Riorda, M. (2016): Cambiando: el eterno comienzo de Argentina, Buenos Aires, Planeta.

Ryan, J. (2004): Avatars of story, Minnesota, University of Minnesota Press.

Salmon C. (2008): Storytelling la máquina de fabricar historias y formatear mentes, Barcelona, Ediciones Península.

Salmon, C. (2011): La estrategia de Sherezade, Barcelona, Península.

Selbin, E. (2012): El poder del relato. Revolución, rebelión, resistencia, Buenos Aires, Interzona.

Simmons, A. (2007): Whoever tells the best stoy wins, New York, Amacom.

Terrasa, E. (1991). "Vida y relato. La narrativa de Isaak Dinesen", en La información como relato. Actas de las V Jornadas Internacionales de Ciencias de la Información, Pamplona, Servicio de Publicaciones de la Universidad de Navarra.

Tilly, C. (2002): Stories, Identities, and Political Change, New York, Rowman \& Littlefield Publishers.

Truby J. (2010): The Anatomy of story. 22 steps to becoming a master storyteller, New York, Faber and Faber. 
Verón, E. (1987): "La palabra adversativa. Observaciones sobre la enunciación política", en E. Verón et al., El discurso político. Lenguajes y acontecimientos. Buenos Aires, Editorial Hachette, pp. 12-26.

Verón, E. y Sigal, S. (2003): Perón o muerte. Los fundamentos discursivos del fenómeno peronista, Buenos Aires, Eudeba.

Vommaro, G. (2017): La larga marcha de Cambiemos: la construcción silenciosa de un proyecto de poder, Buenos Aires, Siglo XXI Editores.

Westen, D. (2007): The political brain: The role of emotion in deciding the fate of the nation, New York, Public Affairs Books.

White H. (1980): "The Value of Narrativity in the Representation of Reality", en Critical Inquiry, 7 (1), pp. 5-27. 